\title{
Taguchi Approach for Determining the Most Essential Aspect in Enhancing the RPL Performance
}

\author{
P.Srikanth, S.Pallam Shetty, K.Venkata Krishna R
}

\begin{abstract}
Wireless Networks to support real time communication is a challenging issue due to limited bandwidth and limited energy. Internet a best-effort model with IPv4 have complication in handling the limited network connections. To prune the network connection problem IPv6 a QoS model has been incorporated. IPv6 implementation using internet over various devices/things connected wirelessly is Internet of Things(IOT). RPL a routing protocol best suits for IOT communication needs to implement best effort model with ICMP highly adaptable for IPv4. A series of experiments have been conducted on Cooja simulator to analyse for enhancement for QoS parameters metric on RPL Routing Protocol. The experimental results yields that no of nodes, Tx Ratio, ICMP intervals and ICMP interval are four factor having an remarkable influence on the QoS Metric of RPL routing protocol. A Design of experiments have been conducted to an optimum level using the Taguchi approach to pick out the most influential factor among the four factors. Taguchi experimental analysis revealed that ICMP time interval as most significant factor for QoS metric in RPL routing protocol for minimizing the energy consumption and enhancing the network lifetime.

Keywords: RPL, QoS Metrics, Tx Ratio, ICMP
\end{abstract}

\section{INTRODUCTION}

In the current scenario with the advent of the Information and Communication Technology (ICT) tools the world is transforming towards the digitalization in which the physical devices needs to be communicated through the internet leads to the new era of Internet of Things(IOT). In IOT the devices needs to sense the data, communicate the data and process the data and timely response to be needed plays an key role in the real world application like military, health care, monitoring, smart city and industries etc..,[1]. The basic approach of building the IOT can be done by utilizing and expanding the existing internet or building the new internet from the scratch. The advisable solution is by utilizing and expanding the existing resources can done by increasing the network connection from transformation of IPv4 to IPv6. Moreover, many physical devices like sensors needs to be connected to increase the scalability of the network.

Manuscript received on August 06, 2021.

Revised Manuscript received on August 23, 2021.

Manuscript published on August 30, 2021.

* Correspondence Author

P. Srikanth*, Ph.D, Department of Computer Science Engineering, Andhra University under Visvesvaraya Scheme, (AP), India.

S. Pallam Shetty, Professor, Department of Computer Science and Systems Engineering, Andhra Engineering College (AP), India.

K.Venkata Krishna R, Research, Department of Computer Science Engineering, IIT Varanasi, (UP), India.

(C) The Authors. Published by Blue Eyes Intelligence Engineering and Sciences Publication (BEIESP). This is an open access article under the CC BY-NC-ND license (http://creativecommons.org/licenses/by-nc-nd/4.0/)
The physical devices embedded with sensing capabilities in leads to implementation of Wireless sensor networks in the IOT. The promising feature is, WSN is the heart of Internet of Things. As we know the WSN are constraint devices with low computational capabilities, low memory, limiting the energy constraints. In order to maintain the maximum network lifetime limiting the energy constraints is an key issue for Low Power Lossy Networks(LLN).

The challenging feature is implementing an efficient routing protocol in IOT environment using IPv6, so RPL(Routing Protocol for Low Power Lossy Networks) is chosen for optimized routing path[2].

RPL is a reactive routing protocol in adapting to the dynamic network transformations. RPL generates an optimal path by using the two objective functions OF0 (Objective Function Zero) and MRHOF(Maximum Rank Hysteresis Objective Function).OF0 function generates the optimized path with minimum hop transmission count and MRHOF uses the ETX for the optimized path but in default cooja simulator uses the OF0 Function.

\section{LITERATURE REVIEW}

Charles, A.S.J et al. [3] mention use of normal routing protocols will create a loss data and so there is a need for retransmission of data. RPL routing protocol with IPv6 is apt for IOT environment. The performance of RPL Routing protocol can be analysed with energy consumption, PDR, divergence time, throughput, etx, latency and control overhead etc.,

Yassien, M.B et al [4] mentioned that adapting to appropriate objective functions among objective function among OF0 in linear and Random topologies. MRHOF out rate OF0 in linear and random topologies in respect to QoS metric factors power and PDR

Maridini, et al [5] mentioned that OF0 and MRHOF are two objective functions in selecting the parent node. The default ICMPv6 control interval is one minute and by modifying control interval values QoS metric is analysed in various scenarios.

Zhang, $\mathrm{T}$ et al [6] mentioned that in the advancement of standards in IOT, IETF specifically proposed RPL for IPv6 in limited power and minimising the cost. They are analysing different settings in a network and RPL performance with factors like energy consumption and latency etc.,

tools.ietf.org (n.d) [7] RPL detailed explains the importance of control message interval timings in regards to energy consumptions and PDR.

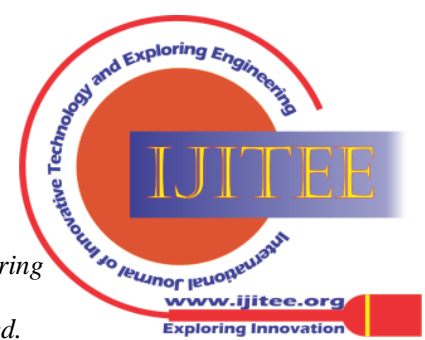


Manikanta, $\mathrm{P}$ et al [8] mentioned that using the Taguchi approach to find out the most appropriate factor that suits for Mobile Adhoc network in DYMO routing protocol.

Jadhao , A.R et al [9] mentioned that in may application in real world are subjected to low power lossy environments. IETF has proposed an routing protocol RPL for LLN using IPv6. Here they are using cooja simulator to analyse RPL Performance in various secenarios

Rao, C.P.V.N.J.M. et al [11] identified Time to Live ( TTL) as the most significant factor in STAR routing protocol by design of experiments conducted using Taguchi approach

\section{RPL PROTOCOL}

RPL(Routing protocol for Low power lossy networks) an reactive routing protocol for energy constraint and cost minimized networks. RPL a distance vector routing protocol based upon the spanning tree approach as Directed Acyclic Graph (DAG) will be constructed. RPL routing protocol have a sink node (Root node) were data to transferred to the leaf node known for formation of Destination Oriented Direct Acyclic Graph(DODAG).

UP: Data from the leaf nodes is transferred to the sink nodes

DOWN: Data from sink nodes is broadcasted towards the leaf nodes.

RANK is distance from root nodes to leaf nodes.

In construction of DODAG in RPL consists of basically two objective functions (a)OF0 function (b)MRHOF function. OF0 uses the Hop count and MRHOF uses the ETX.

DODAG tree construction involves the ICMP control messages

(a)DIO(DODAG Information Object)

(b)DIS(DODAG Information Solicitation)

(c)DAO(DODAG Advertisement Object)

(d)DODAG Acknowledgement

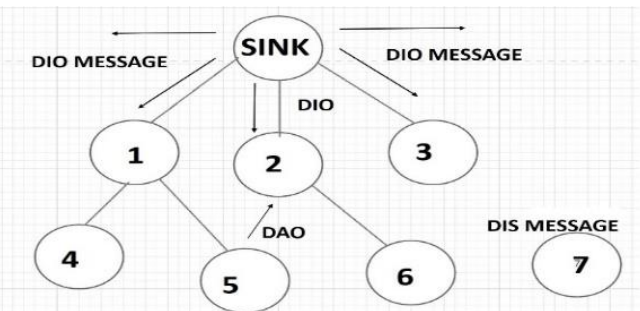

Fig 1 DODAG Formation using control messages

DIO is broadcasted downward for expansion of constructing of tree from root node to leaf nodes. DIS is broadcasted for sink node to join in DODAG. DAO is a request from leaf node to root node. DODAG Ack is a acknowledgement give from root node to leaf node/child node are shown in Fig 1

\section{METHODOLOGY OF STUDY}

\subsection{Methods of Qualitative Research}

Qualitative research approach comprises of three methodologies Simulation, Mathematical and Experimental. As Experimental approach emphasis on practical issues and Mathematical approach is highly confining so simulation approach is chosen. Various Simulator like NS3, Omnet++ and cooja Etc.., were chosen to implement the RPL Routing Protocol but cooja simulator with Contiki-2.7 is chosen as it highly adaptable for IOT Environment the research method was to assess the finding by gathering analysing and comparing data and the drawing conclusion from the findings to establish the significant feature for performance enhancing.

\subsection{Method of Quantative Research}

The approach of this paper is to recognize one ideal factor which have significant role in RPL to minimize the node energy consumption and to maximize the packet delivery ratio. To obtain an ideal factor a set of design of experiments have been conducted in related to Taguchi Approach. A round of experiments have been conducted on four factor with an level of optimization to find out the significant factor which likely to enhance the performance of QoS Metrics.

\subsection{Simulation Software}

Cooja is an IOT friendly simulation software which suits aptly for IOT Stack in the Real-World Environment. Researches can easily analyse impact of different factor on various protocol in real world applications. Cooja tools is used for

a. A new set of designs can be designed on existing protocols

b. Compare study can be done between existing and new design for performance analysis.

c. Analyse the various performance metrics.

d. Newly designed models can be incorporated to real world applications.

\subsection{Setup and Execution of Simulation}

RPL Routing protocol is run upon the cooja simulator on various secenarios by modifying the various inputs. The various scenarios are recreated by changing the inputs and mentioned in Table 1 and simulation Scenarios are shown in Figure 2

Table 1 Parameters used for simulation

\begin{tabular}{|l|l|}
\hline Specification & Values \\
\hline Protocol & RPL \\
\hline Simulation Time & 300 Sec \\
\hline Seed & Random \\
\hline Propogation model & UGDM \\
\hline Rx Ratio & $100 \%$ \\
\hline Tx Ratio & $50 \%, 60 \%, 70 \%$ \\
\hline Mote & Sky Mote \\
\hline No of Nodes & $20,30,40$ \\
\hline ICMP INTERVAL & 10 sec, 20sec, 40sec, 60sec \\
\hline Node Position & Random, Linear \\
\hline Speed & No Speed limit \\
\hline Area & $100 X 100$ \\
\hline Objective Function & OF0 \\
\hline
\end{tabular}




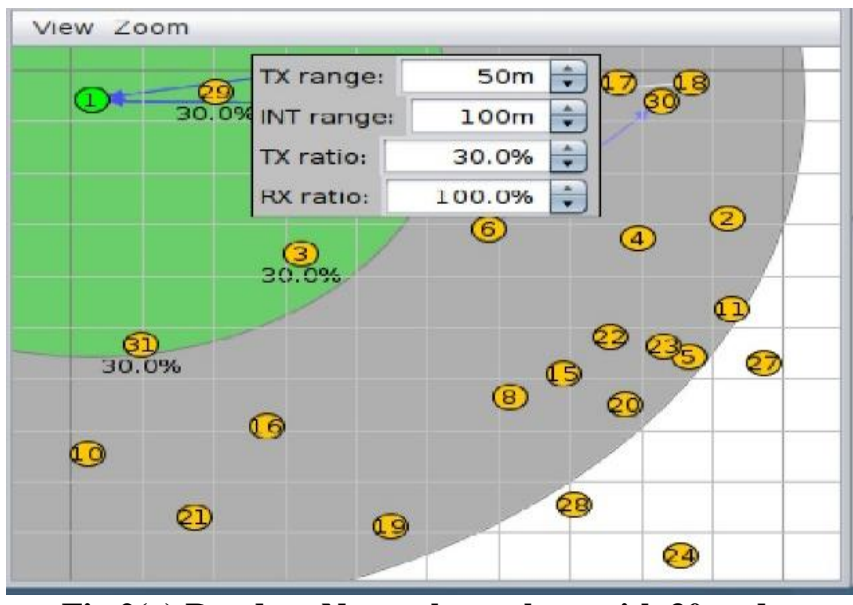

Fig 2(a) Random Network topology with 30 nodes

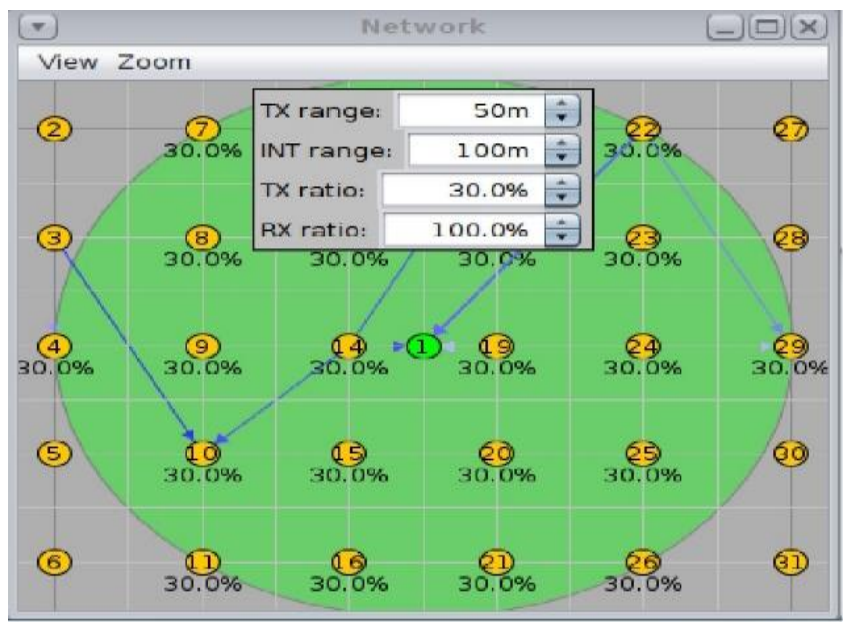

Fig 2(b) Linear Network topology with 30 nodes

\section{FINDINGS AND ANALYSIS}

Using Cooja Simulator RPL Routing Protocol is simulated in various scenarios and identified Number of Nodes, Tx Ratio, ICMP time intervals and topology have an significant impact on two QoS parameter power and Packet Delivery Ratio. In this paper a design of experiment have been run using Taguchi approach to find out the most significant factor is shown in th figure 3

\begin{tabular}{|c|c|c|}
\hline $\begin{array}{c}\text { RPL } \\
\text { Parameters/Nodes JX }\end{array}$ & $\begin{array}{l}\text { DOE } \\
\text { using }\end{array}$ & $\begin{array}{l}\text { Identifying the most } \\
\text { significant factor }\end{array}$ \\
\hline Ratio,ICMP,Topology) & $\begin{array}{c}\text { Taguchi } \\
\text { Approach }\end{array}$ & $\begin{array}{l}\text { among the input } \\
\text { parameters }\end{array}$ \\
\hline
\end{tabular}

Fig 3 Block Diagram of Taguchi Approach

\subsection{Flow Diagram}

The flow diagram illustrates the approach involved by design of experiments run with an optimum level using the Taguchi Approach is shown in the figure 4

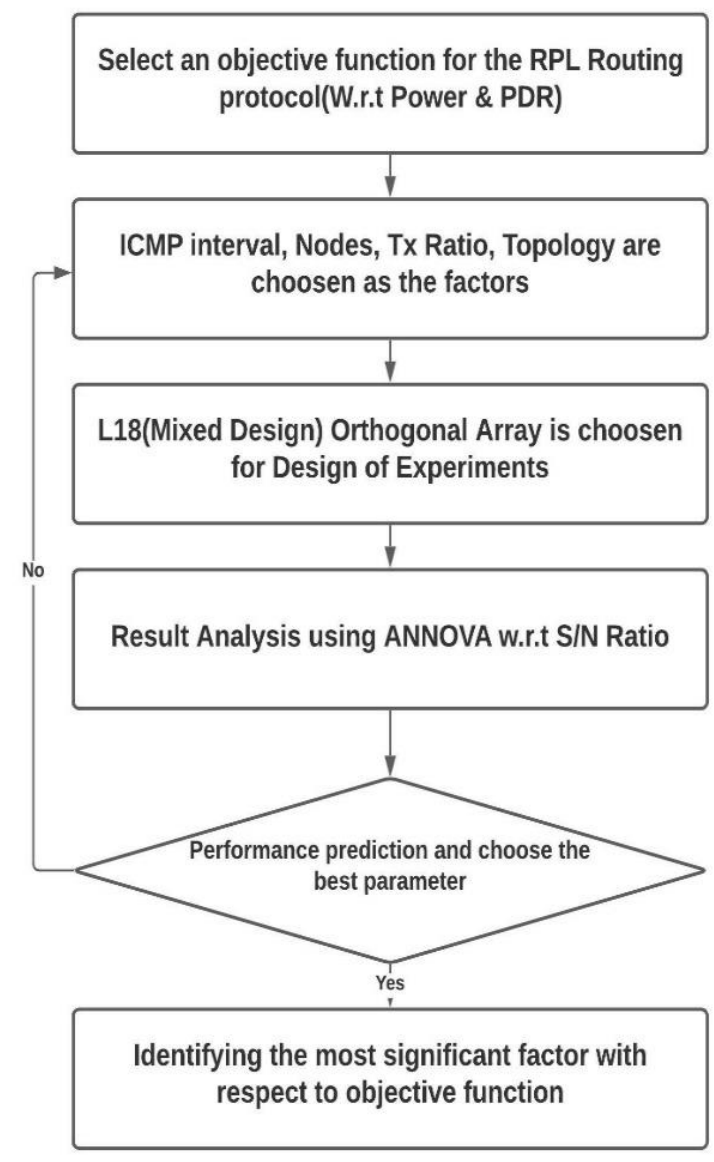

Fig 4 Flow Diagram for Taguchi Approach in RPL

\subsection{Taguchi Design}

An Orthogonal Array L18 (Mixed-Design) with factor ICMP intervals, nodes, Tx Ratio and Topology with 4,3,3,2 levels simultaneously have been identified

\subsection{Orthogonal Array}

An array with 18 set of experiments have been conducted shown in the Table 2

Table 2 Factor wise up to 4 Levels

\begin{tabular}{|l|l|l|l|l|l|}
\hline S.No & Factor & Level 1 & Level 2 & $\begin{array}{l}\text { Level } \\
\mathbf{3}\end{array}$ & $\begin{array}{l}\text { Level } \\
\mathbf{4}\end{array}$ \\
\hline 1 & $\begin{array}{l}\text { ICMP } \\
\text { INTERVALS }\end{array}$ & 10 & 20 & 40 & 60 \\
\hline 2 & NODES & 20 & 30 & 40 & $*$ \\
\hline 3 & TX RATIO & 50 & 60 & 70 & $*$ \\
\hline 4 & TOPOLOGY & RANDOM & LINEAR & $*$ & $*$ \\
\hline
\end{tabular}

An orthogonal array is an mixture of various factors at various levels. Lets us consider experiment 3 in which factor 1 at level 1, factor 2 at level 3, factor 3 at level 3 and factor 4 at level 1 and the power and pdr are shown at columns C5 and $\mathrm{C} 6$ show in the Table 3

\subsection{Analysis on Taguchi Approach}

In an orthogonal Array with respect to C5 and C6 needs to find out the ideal factor

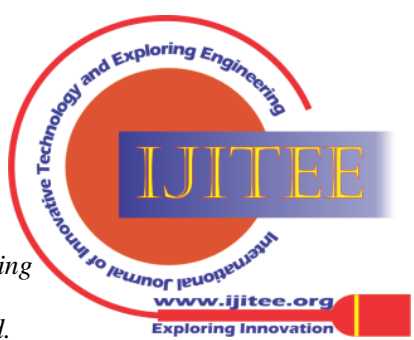


Table 3 L18 Orthogonal Array for Taguchi DOE

\begin{tabular}{|c|c|c|c|c|c|c|}
\hline EXP NO & ICMP INTERVALS & NODES & TX RATIO & TOPOLOGY & POWER & PDR \\
\hline 1 & 10 & 20 & 50 & RANDOM & 2.972 & 0.80732 \\
\hline 2 & 10 & 30 & 60 & LINEAR & 3.054 & 0.90576 \\
\hline 3 & 10 & 40 & 70 & RANDOM & 3.379 & 0.90192 \\
\hline 4 & 20 & 20 & 50 & LINEAR & 2.673 & 0.89756 \\
\hline 5 & 20 & 30 & 60 & RANDOM & 2.732 & 0.81527 \\
\hline 6 & 20 & 40 & 70 & RANDOM & 2.381 & 0.9116 \\
\hline 7 & 40 & 20 & 60 & RANDOM & 1.812 & 0.96018 \\
\hline 8 & 40 & 30 & 70 & LINEAR & 1.693 & 0.9809 \\
\hline 9 & 40 & 40 & 50 & RANDOM & 2.852 & 0.8056 \\
\hline 10 & 60 & 20 & 70 & RANDOM & 1.718 & 0.97968 \\
\hline 11 & 60 & 30 & 50 & RANDOM & 2.894 & 0.777 \\
\hline 12 & 60 & 40 & 60 & LINEAR & 2.928 & 1 \\
\hline 13 & 10 & 20 & 60 & RANDOM & 3.057 & 0.820156 \\
\hline 14 & 10 & 30 & 70 & RANDOM & 2.891 & 0.919401 \\
\hline 15 & 10 & 40 & 50 & LINEAR & 3.577 & 0.795203 \\
\hline 16 & 60 & 20 & 70 & LINEAR & 1.522 & 0.952 \\
\hline 17 & 60 & 30 & 50 & RANDOM & 2.894 & 0.777 \\
\hline 18 & 60 & 40 & 60 & RANDOM & 2.761 & 0.8583 \\
\hline
\end{tabular}

5.4.1 Power: Power consumed by each node over a span of time. We consider the feature "smaller is the Better".

\section{Response Table}

Response Table for Signal to Noise Ratios Smaller is better

\begin{tabular}{lrrrr}
\multicolumn{7}{c}{ ICMP } & & & \\
Level & INTERVALS & NODES & TX RATIO & TOPOLOGY \\
1 & -9.955 & -6.870 & -9.481 & -8.386 \\
2 & -8.268 & -8.290 & -8.575 & -7.810 \\
3 & -6.280 & -9.406 & -6.709 & \\
4 & -7.146 & & & \\
Delta & 3.675 & 2.536 & 2.772 & 0.576 \\
Rank & 1 & 3 & 2 & 4
\end{tabular}

Table 4 Response Table for Power

Response table shown in Table 4 identifies the most significant factor. In Response table the delta value having the least rank is known as the most significant factor form the above table it is clearly observed that ICMP is the most Significant factor

Delta is the difference between the max and min average of signal to noise ratio.

\section{Main Effect Plots for SN Ratio}

The main effect plot for signal to noise ratio graphically visualizes the most significant factor shown in Fig 5

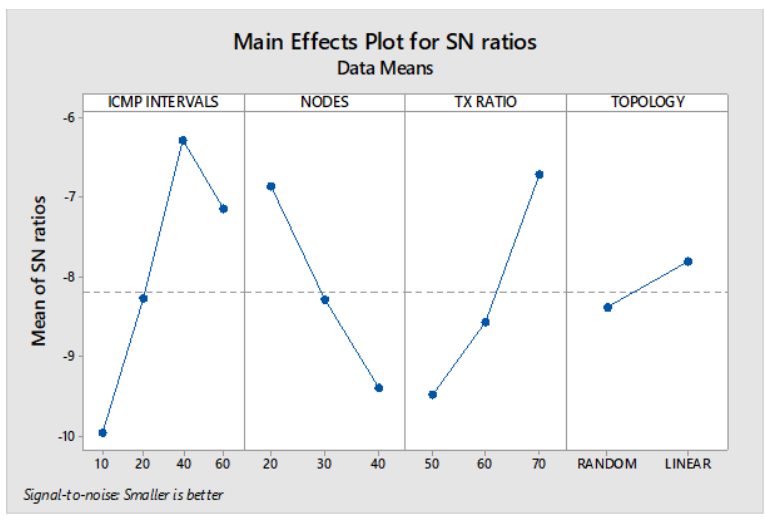

Fig 5 Main Effect Plot for SN Ratio (power)

Retrieval Number: 100.1/ijitee.J941208101021

DOI: $10.35940 /$ ijitee.J9412.08101021

Journal Website: www.ijitee.org
The main effect plot also visualizes ICMP interval as the most significant factor.

\section{Analysis of Variance for SN Ratio}

ANNOVA is statistical tool used for validation to find out the most significant factor which consists of sum of squares, mean of square and Analysis of Variance is shown in the table 5

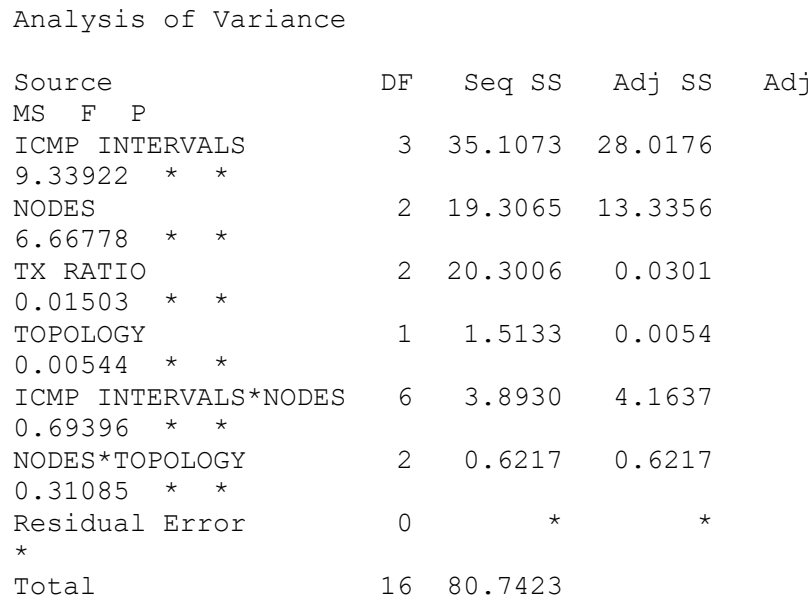

Table 5 Analysis of Variance

\subsubsection{PDR (Packet Delivery Ratio)}

PDR is defined as total no received to total no of packets sent in a network

$P d r=($ total packets recieved $) /($ total packets send $)$

In considering the feature PDR we need to consider "larger is the better".

\section{Response Table}

Response table for the PDR identifies the Tx ratio as the most significant factor show in Table 6

Published By:

Blue Eyes Intelligence Engineering and Sciences Publication

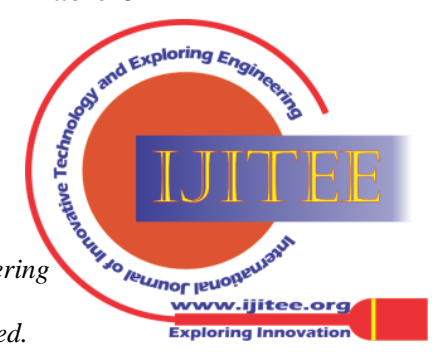


Response Table for Signal to Noise Ratios Larger is better

\begin{tabular}{lrrrr}
\multicolumn{1}{c}{ ICMP } & & & \\
Level & INTERVALS & NODES & TX RATIO & TOPOLOGY \\
1 & -1.3430 & -0.9131 & -1.7715 & -1.2467 \\
2 & -1.1722 & -1.1445 & -1.0060 & -0.7306 \\
3 & -0.7994 & -1.1493 & -0.5339 & \\
4 & -0.8249 & & & \\
Delta & 0.5436 & 0.2362 & 1.2376 & 0.5160 \\
Rank & 2 & 4 & 1 & 3
\end{tabular}

Table 6 Response table for SN Ratio

\section{Main Effect Plots for SN Ratio}

The main effect plots for SN Ratio also visualizes Tx Ratio is the most significant factor for PDR show in Fig 6

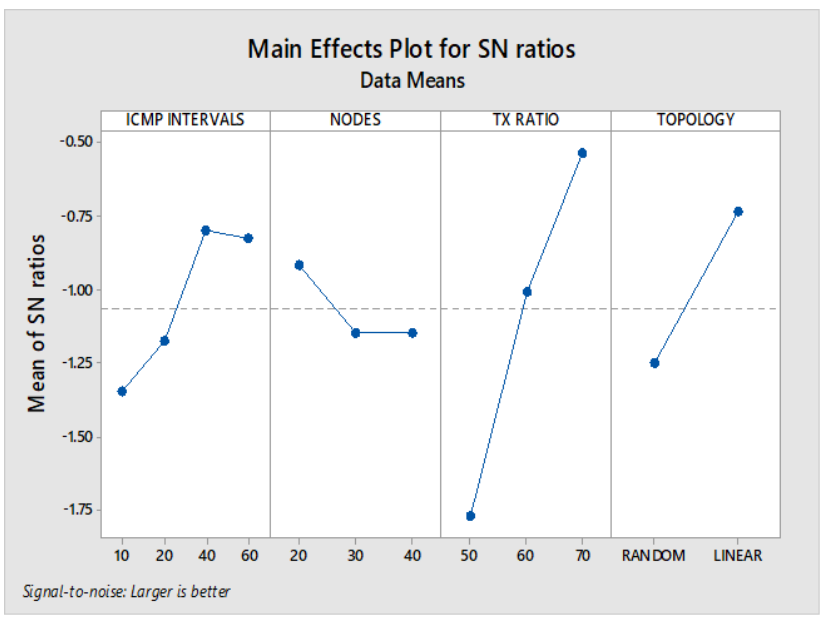

Fig 6 Main effect plot for SN Ratio

\section{Analysis of Variance for SN Ratio}

The analysis of variance for SN ratio for PDR is shown in Table 7

\begin{tabular}{|c|c|c|c|c|c|}
\hline Source & $\mathrm{DF}$ & Seq SS & Adj SS & Adj MS & $\mathrm{F}$ \\
\hline ICMP INTERVALS & 3 & 0.99811 & 1.06583 & 0.355275 & * \\
\hline NODES & 2 & 0.18408 & 0.33914 & 0.169569 & * \\
\hline TX RATIO & 2 & 4.10820 & 1.47472 & 0.737359 & * \\
\hline TOPOLOGY & 1 & 1.32856 & 0.65304 & 0.653041 & * \\
\hline ICMP INTERVALS*NODES & 6 & 0.97221 & 1.57314 & 0.262190 & * \\
\hline NODES*TOPOLOGY & 2 & 0.73505 & 0.73505 & 0.367523 & * \\
\hline Residual Error & 0 & * & * & * & \\
\hline Total & 16 & 8.32621 & & & \\
\hline
\end{tabular}

Table 7 Analysis of variance for SN Ratio

\section{CONCLUSION AND FUTURE SCOPE}

In this paper a design of experiments were conducted basing on Taguchi approach to an optimum level in order to find out the ideal for RPL Routing Protocol in regards to QoS metrics. The experimental results reveals that among the four factors ICMP intervals, no of nodes, Tx Ratio and Network topology its identified that ICMP time interval as the most significant factor in regards to power and Tx Ratio in regards to Packet Delivery Ratio. As RPL is a Routing Protocol for Low Power Lossy Networks (LLN) the key constraint is minimize the energy consumption. So in this contrast experimental result reveals the ICMP interval is the most significant factor for minimizing the energy consumption and enhance the network lifetime.The work may further refined soft computing technique to convert the static ICMP time interval value to a dynamic value adapting to the network environment.

\section{REFERENCES}

1. H. Lamaazi, N. Benamar, A. J. Jara, L. Ladid and D. El Ouadghiri, "Challenges of the Internet of Things: IPv6 and Network Management," 2014 Eighth International Conference on Innovative Mobile and Internet Services in Ubiquitous Computing, 2014, pp. 328-333, doi: 10.1109/IMIS.2014.43.

2. S. Balandin, S. Andreev and Y. Koucheryavy. "Internet of things, smart spaces, and next generation networking". Berlin: Springer. (2013).

3. Charles, A.S.J. and Kalavathi, P. (2018). QoS Measurement of RPL using Cooja Simulator and Wireshark Network Analyser. www.ijcseonline.org, [online] 06(04), pp.283-291.

4. Yassien, M.B., Alzoubi, O., Shatnawi, M. and Rawashdeh, A.A. (2019). Performance analysis of RPL objective functions. Proceedings of the Second International Conference on Data Science, E-Learning and Information Systems - DATA '19.

5. Mardini, W., Aljawarneh, S., Al-Abdi, A. and Taamneh, $\mathrm{H}$ (2018). Performance evaluation of RPL objective functions for different sending intervals. [online] IEEE Xplore. Available at: https://ieeexplore.ieee.org/document/8355323 [Accessed 2 Aug. 2021].

6. Zhang, T. and Li, X. (2014). Evaluating and analyzing the performance of RPL in contiki. Proceedings of the first international workshop on Mobile sensing, computing and communication MSCC '14.

7. $\quad$ tools.ietf.org. (n.d.). RPL: IPv6 Routing Protocol for Low power and Lossy Networks. [online] Available at: https://tools.ietf.org/id/draftietf-roll-rpl-13.html [Accessed 2 Aug. 2021].

8. MANIKANTA, P. \& Setty, s.Pallam. (2018). TAGUCHI DESIGN OF EXPERIMENTS APPROACH TO FIND THE MOST SIGNIFICANT FACTOR OF DYMO ROUTING PROTOCOL IN MOBILE AD HOC NETWORKS. i-manager's Journal on Wireless Communication Networks. 7. 1. 10.26634/jwcn.7.1.14971.

9. Jadhao, A.R. and Solapure, S.S. (2017). Analysis of routing protocol for Low Power and Lossy Networks (RPL) using Cooja simulator. [online] IEEE Xplore. Available at: https://ieeexplore.ieee.org/document/8300183 [Accessed 2 Aug. 2021].

10. Attada, V. and Pallam Setty, S. (2015). Cross Layer Design Approach to Enhance the Quality of Service in Mobile Ad Hoc Networks. Wireless Personal Communications, 84(1), pp.305-319.

11. Rao, C.P.V.N.J.M. (n.d.). DOE to Identify the Most Significant Factor to Enhance the Performannce of Defacto star for Manets to Support Real Time Communincaton.imanager puvlications.com.https://imanagerpublications.com/article/16554/ [Accessed 4 Aug. 2021].

\section{AUTHORS PROFILE}

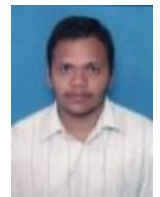

P. Srikanth, current doing his Ph.D in CSE at Andhra University under Visvesvaraya Scheme.

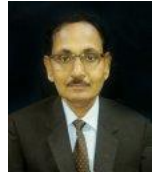

S. Pallam Shetty, working as the Professor in CSSE Department at Andhra Engineering College for the past 30 Years.

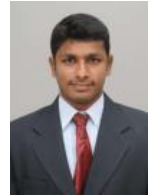

K.Venkata Krishna R, done his M.Tech in IIT Chennai. He Presently doing research in machine learning in department of cse at IIT Varanasi 